\title{
Fundamental Study on Mechanisms of Thermal Decomposition and Oxidation of Aluminium Hydride
}

\author{
Muye Feng ${ }^{\mathrm{a}}$, Heping Li ${ }^{\mathrm{b}}$, Qian Mao ${ }^{\mathrm{c}}$, Kai H. Luo ${ }^{\mathrm{a}, *}$, Paul Hellier ${ }^{\mathrm{a}}$ \\ ${ }^{a}$ Department of Mechanical Engineering, University College London, Torrington Place, London \\ WC1E 7JE, UK \\ ${ }^{b}$ School of Science, Hangzhou Dianzi University, Hangzhou 310018, China \\ c Institut für Technische Verbrennung, RWTH Aachen University, 52056 Aachen, Germany
}

\section{ABSTRACT}

Aluminium hydride $\left(\mathrm{AlH}_{3}\right)$ has a great potential for a variety of propulsion and energy storage applications. In this study, the ReaxFF reactive force field molecular dynamics simulation is employed to investigate the fundamental reaction mechanisms of thermal decomposition and oxidation of $\mathrm{AlH}$. The effects of an oxide layer and/or defect are examined, and the detailed process and mechanism of $\mathrm{H}_{2}$ and $\mathrm{H}_{2} \mathrm{O}$ formation are illustrated. With the presence of an oxide layer, $\mathrm{H}_{2}$ production of core-shell $\mathrm{AlH}_{3}$ during the thermal decomposition is slower than that of bare $\mathrm{AlH}_{3}$. As far as oxidation is concerned, any defect enhances the initiation of core-shell $\mathrm{AlH}_{3}$ oxidation and accelerates the oxidation at the early stage of the reaction. Additionally, the presence of $\mathrm{O}_{2}$ promotes the production of $\mathrm{OH}$. Both thermal decomposition and oxidation of core-shell $\mathrm{AlH} 3$ show significant $\mathrm{H}_{2} \mathrm{O}$ production, and $\mathrm{H}_{2} \mathrm{O}$ is preferentially formed compared with $\mathrm{H}_{2}$ at the beginning of the reaction. The results reveal that the structural evolution of core-shell $\mathrm{AlH}_{3}$ during the thermal decomposition

* Corresponding author at: Department of Mechanical Engineering, University College London, Torrington Place, London WC1E 7JE, UK. Tel: +44 (0)20 7679 3916. E-mail address: k.luo@ucl.ac.uk (Kai H. Luo) 
and oxidation proceed in three distinctive stages, respectively. It is found that during the oxidation, dehydrogenation and oxidation proceed simultaneously although the oxidation rate is limited during the dehydrogenation period.

\section{INTRODUCTION}

Aluminium hydride ( $\mathrm{AlH}_{3}$, also known as alane) is a potential high energy and hydrogen storage media for a wide range of applications, including solid or hybrid rocket propulsion, explosive and hydrogen source for low temperature fuel cells [1-5]. AlH3 has a large gravimetric and volumetric hydrogen capacity (10.1 wt. \% and $0.148 \mathrm{~g} / \mathrm{ml}$, respectively), which is twice as much as the value of liquid hydrogen $(0.070 \mathrm{~g} / \mathrm{ml})$, and rapid low temperature decomposition kinetics (below $100^{\circ} \mathrm{C}$ ) [6-8]. $\mathrm{AlH}_{3}$ is known to exist in seven different polymorphs, however, $\alpha-\mathrm{AlH}_{3}$ has been considered to be the most desirable polymorph in practical applications as it is the most stable [2, 9, 10]. $\alpha-\mathrm{AlH}_{3}$ is generally metastable due to the presence of the surrounding alumina layer, which effectively prevents dehydrogenation at room temperature [6]. In 1947, AlH3 was firstly prepared in an ether solvated form by Finholt et al. [11]. It was then evaluated in the early 1960s for military applications and was formulated into propellants. $\mathrm{AlH}_{3}$ is considered as one of the most interesting additives in space propulsion. When $\mathrm{AlH}_{3}$ is added into solid propellant formulations, it can decrease the overall molecular weight with expected $\mathrm{H}_{2}$ formation in the combustion gases and provide a higher combustion heat enhancing the rocket performance and specific impulse by more than 100 N.s.kg ${ }^{-1}$ compared with aluminium [12-14]. However, the low thermal stability of $\mathrm{AlH}_{3}$ leads to the generation of excessive amounts of hydrogen gas in the solid propellant during storage. Hence, by the early 1970s, most of the development work in the USA was disbanded as a result of the instability and high production costs of $\mathrm{AlH}_{3}$ [15]. Recently, interest in $\mathrm{AlH}_{3}$ has been renewed due to advances in safe and cheap production methods and the increase in thermal stability thus improvements in storage [16]. 
The preparation, characterization, decomposition kinetics and vacuum thermal stability (VTS) of $\mathrm{AlH}_{3}$ were investigated in a great many literatures. Paraskos et al. [17] studied the thermal decomposition characteristics of $\mathrm{AlH}_{3}$ and found that during the heating process, $\mathrm{AlH}_{3}$ rapidly decomposes at about $180^{\circ} \mathrm{C}$ with a weight loss of $10 \mathrm{wt} . \%$, which is consistent with the theoretical hydrogen content. Tarasov et al. [18] investigated the isothermal decomposition of $\mathrm{AlH} 3$ using nuclear magnetic resonance (NMR) and the results suggested that the thermal decomposition process is divided into three stages, i.e. the induction period, the acceleration period and the deceleration period. The activation energies for the three stages are 97, 108 and $112 \mathrm{~kJ} / \mathrm{mol}$, respectively. To further understand the dehydrogenation of $\mathrm{AlH}_{3}$, Ismail and Hawkins [16] studied the kinetics and mechanism of thermal decomposition of $\mathrm{AlH}_{3}$ in argon by thermogravimetric (TG) analysis. The results revealed that the decomposition is initiated by the liberation of hydrogen from an external surface and pre-existing pores and cracks. Additionally, this decomposition consisted of two major steps: the slowest step controlled by the solid-state nucleation of aluminium crystals, which is the rate-determining step, and the fastest step due to the crystal growth, which is postulated as the growth of an aluminium layer toward the particle centre. Weiser et al. [19] carried out thermoanalytical oxidation experiments with $\mathrm{AlH}_{3}$ and discovered that the particles presented similar oxidation behaviour as $\mathrm{Al}$ nanoparticles with a diameter of less than $100 \mathrm{~nm}$ after dehydrogenation. This oxidation included a chemically controlled reaction between 650 and $850 \mathrm{~K}$ and a subsequently diffusion controlled reaction step above $900 \mathrm{~K}$. Furthermore, the previous literatures also demonstrated that the characteristics of thermal decomposition of $\mathrm{AlH}_{3}$ depends on many factors including particle size, impurities, crystal defects, temperature, heating rate and so on $[15,16,18,20$ 23].

To summarize, the thermal decomposition and oxidation of $\mathrm{AlH}_{3}$ has been extensively studied by experiments but the microscopic process and underlying mechanisms are still poorly understood. Especially, those fast-changing high-temperature $\mathrm{AlH}_{3}$ reactions taken place in propulsion systems 
are difficult or even impossible to be explored by the existing experimental techniques. Fundamental research needs to be done to gain a physicochemical insight of $\mathrm{AlH}_{3}$ reactions, which could be beneficial for optimizing the design and application of $\mathrm{AlH}_{3}$ fuel/propellant and energy storage systems. The present research focuses on the high-temperature thermal decomposition and oxidation reactions of $\mathrm{AlH}_{3}$ applicable to propulsion applications. In this study, ReaxFF reactive force field molecular dynamics (MD) simulations are performed to investigate the fundamental reaction mechanisms of thermal decomposition and oxidation of $\mathrm{AlH}_{3}$ at the atomic level. The effects of the oxide layer and defect are also examined, with both gas and solid phase reactions scrutinised to obtain the overall microscopic understanding of the $\mathrm{AlH}_{3}$ reaction process.

\section{METHODS}

\subsection{ReaxFF Reactive Force Field Molecular Dynamics (MD) Simulation}

The ReaxFF MD is a bond-order concept based method, which is able to model dissociation, transition and formation of chemical bonds within a reactive system. Force field parameters are trained against quantum mechanics (QM) calculations or/and experimental data. Compared with QM-based methods, it is computationally much more cost-efficient and retains a comparable level of accuracy. Hence, ReaxFF is becoming increasingly popular for studying long-time large-scale reactive MD simulations, which are impractical or impossible to attain using QM methods. To allow for connectivity changes, ReaxFF bond orders are computed directly from interatomic distances (Equation (1)) and continually updated at every time step [24].

$$
\begin{aligned}
\mathrm{BO}_{i j} & =\mathrm{BO}_{i j}^{\sigma}+\mathrm{BO}_{i j}^{\pi}+\mathrm{BO}_{i j}^{\pi \pi} \\
& =\exp \left[p_{\mathrm{bo} 1}\left(r_{i j} / r_{o}^{\sigma}\right)^{p_{\mathrm{bo} 2}}\right]+\exp \left[p_{\mathrm{bo} 3}\left(r_{i j} / r_{o}^{\pi}\right)^{p_{\mathrm{bo} 4}}\right]+\exp \left[p_{\mathrm{bo} 5}\left(r_{i j} / r_{o}^{\pi \pi}\right)^{p_{\mathrm{bo} 6}}\right]
\end{aligned}
$$


where $\mathrm{BO}$ is the bond order between atoms $i$ and $j, r_{i j}$ is interatomic distance, $r_{o}$ terms are equilibrium bond lengths, and $p_{\text {bo }}$ terms are empirical parameters. Equation (2) shows the general expression of energy contributions to the ReaxFF potential [25].

$E_{\mathrm{system}}=E_{\mathrm{bond}}+E_{\mathrm{over}}+E_{\mathrm{under}}+E_{\mathrm{lp}}+E_{\mathrm{val}}+E_{\mathrm{tor}}+E_{\mathrm{vdWaals}}+E_{\text {Coulomb }}$

where $E_{\text {system, }} E_{\text {bond }}, E_{\text {over, }} E_{\text {under, }} E_{\mathrm{lp}}, E_{\mathrm{val}}, E_{\mathrm{tor}}, E_{\mathrm{vdWaals}}$ and $E_{\text {Coulomb }}$ represent total energy, bond energy, overcoordination energy penalty, undercoordination stability, lone pair energy, valence angle energy, torsion angle energy, van der Waals energy, and Coulomb energy, respectively.

Further information on the ReaxFF formulation and development is given in previous literature [24, 26-28]. The ReaxFF MD has proven to be an efficient and powerful method for studying various oxidation systems [29-35].

\subsection{Simulation Details}

The REAXC package embedded in LAMMPS [36, 37] is used for performing all the ReaxFF MD simulations. A parameter set for $\mathrm{Al} / \mathrm{C} / \mathrm{H} / \mathrm{O}$ interactions [38] extended by the original $\mathrm{Al} / \mathrm{H}$ description [39] which was specifically parameterized for aluminium hydride is chosen as a suitable force field. Four three-dimensional and cubic systems, specifically, two for thermal decomposition and two for oxidation, are built with all-direction periodic boundary conditions. The size of the simulation box is $150 \AA \times 150 \AA \times 150 \AA$. A spherical $\alpha$-AlH3 nanoparticle wrapped by a thin $\alpha$ alumina shell is constructed in order to approximate the real-world or experimental condition due to the existence of the oxide layer on aluminium hydride. For the same purpose, the effect of the oxide layer defect is also considered. It is noted that initial tests show the evolution of a nanoscale $\mathrm{AlH}_{3}$ crystal structure to a spherical structure at a very early stage of the reaction, so a spherical nanoparticle model is adopted. Although the $\mathrm{AlH}_{3}$ sample used in the real experiment is cuboid shaped [16, 40], the huge difference of the employed particle size between the present simulation 
(nano-size) and real experiment (micro-size) makes the effect of geometry much less important. Due to the fact that the specific surface area of nanoparticle is much larger, the reaction kinetics is expected to be enhanced compared with using the actual micron-size $\mathrm{AlH}_{3}$.

The detailed core-shell model is prepared following these steps: (1a) cut a $5 \mathrm{~nm}$ diameter $\alpha$ $\mathrm{AlH}_{3}$ nanoparticle from the crystal structure; (1b) relax the nanoparticle for $100 \mathrm{ps}$; (1c) cut the $3 \mathrm{~nm}$ diameter core from the relaxed $\mathrm{AlH}_{3}$ nanoparticle; (2a) cut a $6 \mathrm{~nm}$ diameter $\alpha$-alumina nanoparticle from the crystal structure; (2b) relax the nanoparticle for 100 ps; (2c) cut the 0.4 nm thickness shell from the relaxed $\alpha$-alumina nanoparticle (radius range from $1.5 \mathrm{~nm}$ to $1.9 \mathrm{~nm}$ ); (3a) combine the $\mathrm{AlH}_{3}$ core and $\mathrm{Al}_{2} \mathrm{O}_{3}$ shell together; (3b) relax the core-shell structure for 200 ps. After Step 1b and 2b, the average diameter of the relaxed $5 \mathrm{~nm}$ diameter $\alpha$-AlH3 nanoparticle and $6 \mathrm{~nm}$ diameter $\alpha$ alumina nanoparticle is about $4.7 \mathrm{~nm}$ and $6.1 \mathrm{~nm}$, respectively. It is therefore proved that the initial cutting size of $\alpha-\mathrm{AlH}_{3}$ and $\alpha$-alumina from their crystal structures is able to eliminate the edge effect during relaxation and more than enough to eventually obtain a relaxed $3 \mathrm{~nm}$ diameter $\mathrm{AlH}_{3}$ spherical core and $0.4 \mathrm{~nm}$ thickness alumina annular shell. Because a nano-sized particle is adopted, in order to create a thin shell with respect to the core, the shell thickness is attempted starting from $0.1 \mathrm{~nm}$ using the relaxed $\alpha$-alumina nanoparticle. It turns out that the size of the thinnest layer that can maintain the complete shell structure is $0.4 \mathrm{~nm}$, whereas the shell has undesired large or small hollow areas at $0.1,0.2$ or $0.3 \mathrm{~nm}$. Thus, a $0.4 \mathrm{~nm}$ thickness oxide shell is chosen because it is neither too thick compared with the $\mathrm{AlH}_{3}$ core nor too thin to lose the $\mathrm{Al}_{2} \mathrm{O}_{3}$ structure. Figure 1a depicts the nanoparticle structures and a typical simulation system. For the defect-containing case (Figure 1a3), a small hole is created throughout the oxide shell at Step (3a) and then relax the nanoparticle for 100 ps. The bare $\mathrm{AlH}_{3}$ nanoparticle case simply relaxes the structure produced after Step (1c) for another 50 ps. All the relaxation processes are performed at $300 \mathrm{~K}$ under NVT ensemble. Each specified relaxation time depends on when the potential energy reaches a stable value, and the corresponding 
potential energy profiles are displayed in Figure 1b. The detailed configuration for each simulation system is summarized in Table 1.
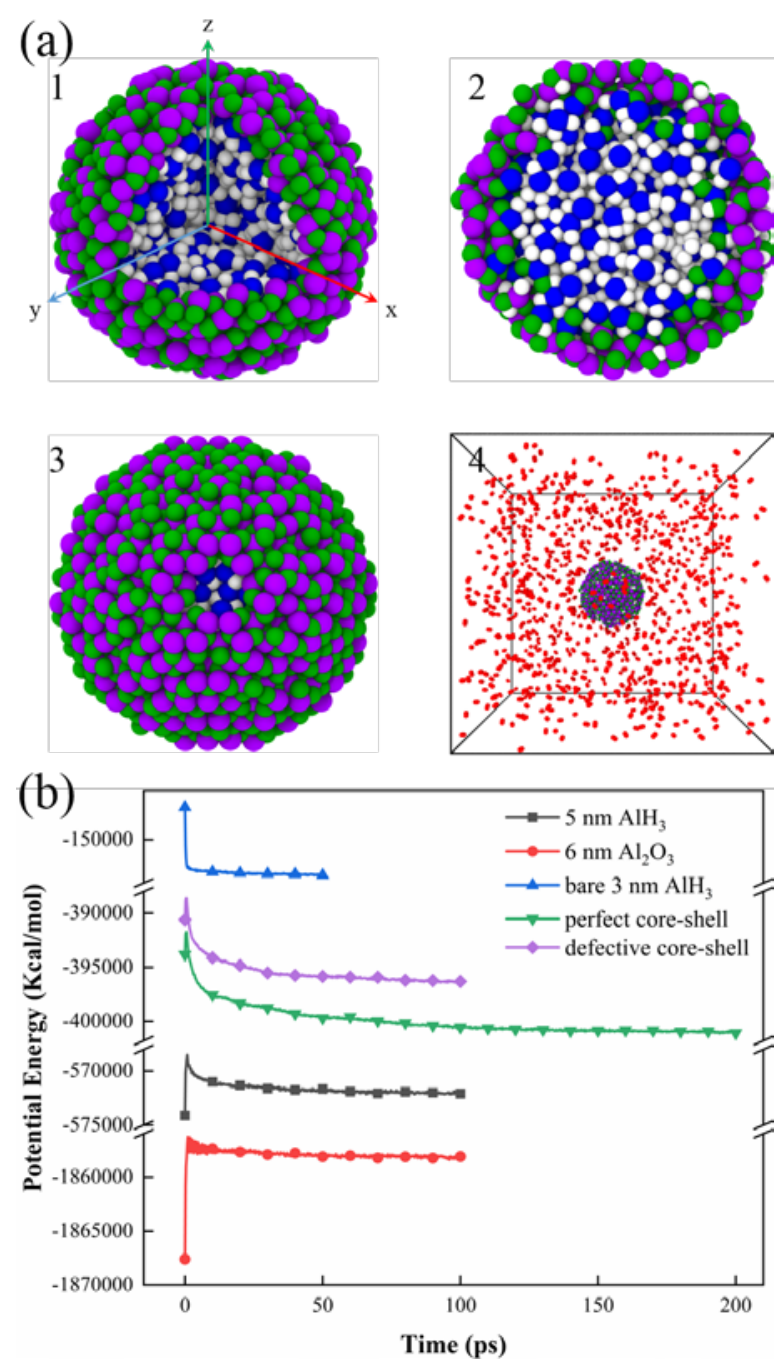

Figure 1. (a) Nanoparticle structures and a typical simulation system: 1. core-shell structure (Step 3a); 2. central cross section of relaxed core-shell nanoparticle (Step 3b); 3. core-shell nanoparticle with a defect; 4. oxidation simulation system. Atoms colouring scheme: core Al - blue; shell Al purple; $\mathrm{H}$ - white; shell $\mathrm{O}$ - green; molecular oxygen $\mathrm{O}$ - red. (b) Potential energy profiles of relaxation processes.

Table 1. Configuration details of simulation systems.

\begin{tabular}{lllll}
\hline Case & System & NP Structure & No. of $\mathrm{O}_{2}$ & No. of Atoms \\
\hline
\end{tabular}




\begin{tabular}{lclcc}
\hline 1 & Thermal & bare $3 \mathrm{~nm} \mathrm{AlH}_{3}$ & 0 & 2097 \\
2 & Decomposition & $3 \mathrm{~nm} \mathrm{AlH}_{3}+0.4 \mathrm{~nm} \mathrm{Al}_{2} \mathrm{O}_{3}$ & 0 & 3772 \\
\hline 3 & \multirow{2}{*}{ Oxidation } & $3 \mathrm{~nm} \mathrm{AlH}_{3}+0.4 \mathrm{~nm} \mathrm{Al}_{2} \mathrm{O}_{3}$ & 1000 & 5772 \\
4 & & $3 \mathrm{~nm} \mathrm{AlH}_{3}+0.4 \mathrm{~nm} \mathrm{Al}_{2} \mathrm{O}_{3}+$ Defect & 1000 & 5751 \\
\hline
\end{tabular}

After the relaxation, NVT simulations at 2000, 2500 and $3000 \mathrm{~K}$ for thermal decomposition and NVE simulations starting from $300 \mathrm{~K}$ for oxidation are conducted for $500 \mathrm{ps.} \mathrm{The} \mathrm{damping} \mathrm{constant}$ for NVT simulations is $100 \mathrm{fs}$ and the time step employed in this study is $0.2 \mathrm{fs}$. The bonding and trajectory results are recorded at a frequency of $0.2 \mathrm{ps.} \mathrm{A} \mathrm{commonly} \mathrm{used} 0.3$ bond order cutoff value is adopted for analysing species formed during the simulation. The visualization of simulation results is processed by OVITO [41].

\section{RESULTS AND DISCUSSION}

\subsection{Thermal Decomposition of Bare and Perfect Core-Shell $\mathrm{AlH}_{3}$}

\subsubsection{Gas Products Formation}

The process and mechanism of hydrogen formation are of great interest in $\mathrm{AlH}_{3}$ reactions. An illustration of how $\mathrm{H}_{2}$ is typically released from bare $\mathrm{AlH}_{3}$ is shown in Figure 2a. Along with the diffusion of $\mathrm{H}$ atoms, two surface $\mathrm{H}$ atoms combine with each other and are released as a $\mathrm{H}_{2}$ molecule mainly in four formats. They can be both adhered to the same Al atom before ejecting (Figure 2a1), or bonded together first with one of them attached on an $\mathrm{Al}$ atom and then leave this $\mathrm{Al}$ atom (Figure 2a2). Alternatively, the two $\mathrm{H}$ atoms can be separately from (Figure 2a3) or shared by (Figure 2a4) two adjacent $\mathrm{Al}$ atoms prior to $\mathrm{H}_{2}$ discharge. The situation is similar for $\mathrm{H}_{2}$ production in the perfect core-shell $\mathrm{AlH}_{3}$ case. As seen in Figure 1a2, during the relaxation, a small amount of $\mathrm{H}$ atoms in the core $\mathrm{AlH}_{3}$ have already diffused into the oxide shell and even to the surface of nanoparticle. Additionally, a thin core-shell interface consisting of both core $\mathrm{Al} / \mathrm{H}$ and shell $\mathrm{Al} / \mathrm{O}$ atoms can be identified. However, the interface and effect of thickness of the oxide shell layer are 
not studied in this research, which will be investigated in the follow-on work. As the reaction proceeds, more $\mathrm{H}$ atoms diffuse through the oxide shell to the surface. The subsequent procedure of $\mathrm{H}_{2}$ release is as described in the case of bare $\mathrm{AlH}_{3}$, but the $\mathrm{H}$ atoms could also be adhered to $\mathrm{O}$ and/or $\mathrm{Al}$ atoms. Due to the existence of the oxide layer, $\mathrm{O}$ atoms are present and $\mathrm{H}_{2} \mathrm{O}$ formation is observed, where Figure $2 \mathrm{~b}$ demonstrates the generation steps. Initially, surface $\mathrm{H}$ and $\mathrm{O}$ atoms in close proximity to one another adhere to the same $\mathrm{Al}$ atom (Figure 2b1). Next, they move closer to each other (Figure 2b2) until the $\mathrm{H}$ atom is bonded directly to the $\mathrm{O}$ atom (Figure $2 \mathrm{~b} 3$ ). Following this, a further nearby $\mathrm{H}$ atom, also attracted by the $\mathrm{O}$ of $\mathrm{OH}$, bonds with the $\mathrm{OH}$ group to form a $\mathrm{H}_{2} \mathrm{O}$ unit (Figure 2b4). Finally, the preformed $\mathrm{H}_{2} \mathrm{O}$ unit disengages from the $\mathrm{Al}$ atom as an independent $\mathrm{H}_{2} \mathrm{O}$ molecule. It is found that the $\mathrm{H}_{2} \mathrm{O}$ unit could slide on the surface for a while before departing from an $\mathrm{Al}$ atom. Moreover, there is a simpler way of producing $\mathrm{H}_{2} \mathrm{O}$, which directly starts from the step of Figure $2 \mathrm{~b} 3$. The $\mathrm{OH}$ involved in this way is pre-existing and integrated during the diffusion of atoms.

(a)

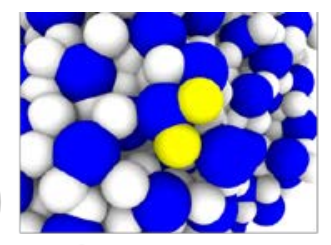

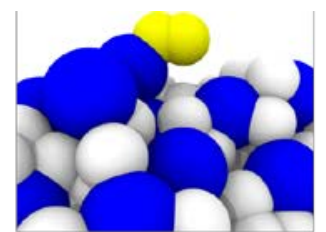

2

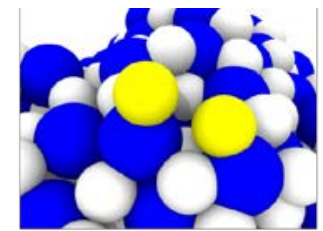

3

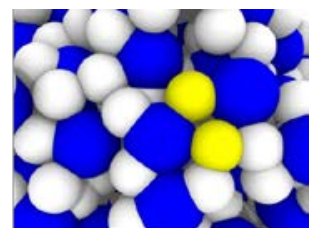

4

(b)

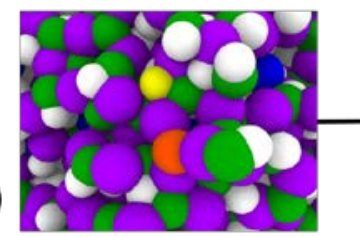

1

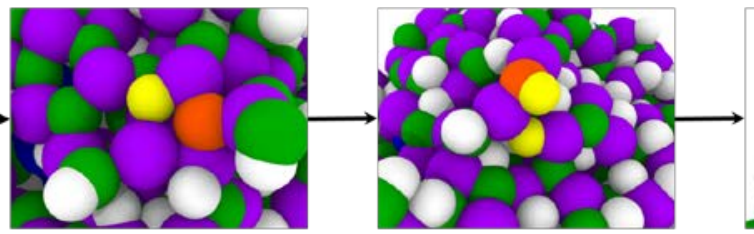

3

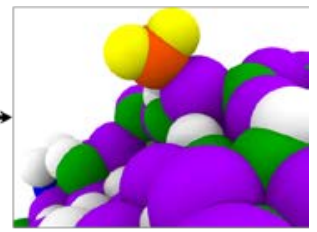

4

Figure 2. Illustration of formation of (a) $\mathrm{H}_{2}$ from bare $\mathrm{AlH}_{3}$. Before the $\mathrm{H}_{2}$ release, two surface $\mathrm{H}$ atoms can be: 1 . both adhered to the same $\mathrm{Al}$ atom; 2 . bonded together first with one of them attached on an $\mathrm{Al}$ atom; 3. separately from two adjacent $\mathrm{Al}$ atoms; 4. shared by two adjacent $\mathrm{Al}$ 
atoms. (b) $\mathrm{H}_{2} \mathrm{O}$ from perfect core-shell $\mathrm{AlH}_{3}$. Before the $\mathrm{H}_{2} \mathrm{O}$ release: 1 . surface $\mathrm{H}$ and $\mathrm{O}$ atoms in close proximity to one another adhere to the same $\mathrm{Al}$ atom; 2. they move closer to each other; 3 . the $\mathrm{H}$ atom is bonded directly to the $\mathrm{O}$ atom; 4. a further nearby $\mathrm{H}$ atom also attracted by the $\mathrm{O}$ of $\mathrm{OH}$, bonds with the $\mathrm{OH}$ group to form a $\mathrm{H}_{2} \mathrm{O}$ unit. The highlighted $\mathrm{H}$ and $\mathrm{O}$ atoms are in yellow and orange, respectively.

The number of $\mathrm{H}_{2}$ molecules produced over time from the thermal decomposition of perfect core-shell $\mathrm{AlH}_{3}$ and bare $\mathrm{AlH}_{3}$, and the number of $\mathrm{H}_{2}$ and $\mathrm{H}_{2} \mathrm{O}$ molecules from thermal decomposition of perfect core-shell $\mathrm{AlH}_{3}$ at 2000, 2500 and $3000 \mathrm{~K}$ are exhibited in Figure 3a and Figure 3b, respectively. In general, the decomposition reactions are temperature dependent that high temperature enhances the thermal decomposition with a faster reaction rate. This temperature dependency relationship is also confirmed by many experimental studies $[9,18,20,42]$. Because the $\mathrm{H}$ atoms of $\mathrm{AlH}_{3}$ have to travel across the oxide layer to the nanoparticle surface, this resistance makes $\mathrm{H}_{2}$ production of perfect core-shell $\mathrm{AlH}_{3}$ slower than bare $\mathrm{AlH}_{3}$, which is consistent with the previous experimental literature [43]. It is noticed from Wang et al. [44] that the thickness of oxide layer has a significant impact on the hydrogen release rate with an order of magnitude reduction by increasing the layer thickness from 1 to $3 \mathrm{~nm}$, which is not that remarkable in Figure 3a. This can be attributed to the thickness difference between the oxide shells in Wang et al's (1-3 nm) and the present study (0-0.4 nm). The level of the resistance created by the shell for the hydrogen release should be comparable to the shell volume rather than thickness because the core $\mathrm{H}$ atoms do not simply travel along the shortest thickness line to cross the shell. Instead, they go through the whole shell area. Furthermore, for the same amount of increasing of the shell thickness, the shell volume increases much more (cubic expansion) with respect to the thickness increment, resulting in much stronger resistance for the hydrogen release. Therefore, the shell thickness discrepancy of 1-3 and 0$0.4 \mathrm{~nm}$ would make a very huge difference between the resulting resistances for the hydrogen release. Detailed quantitative relationship needs further investigations. 

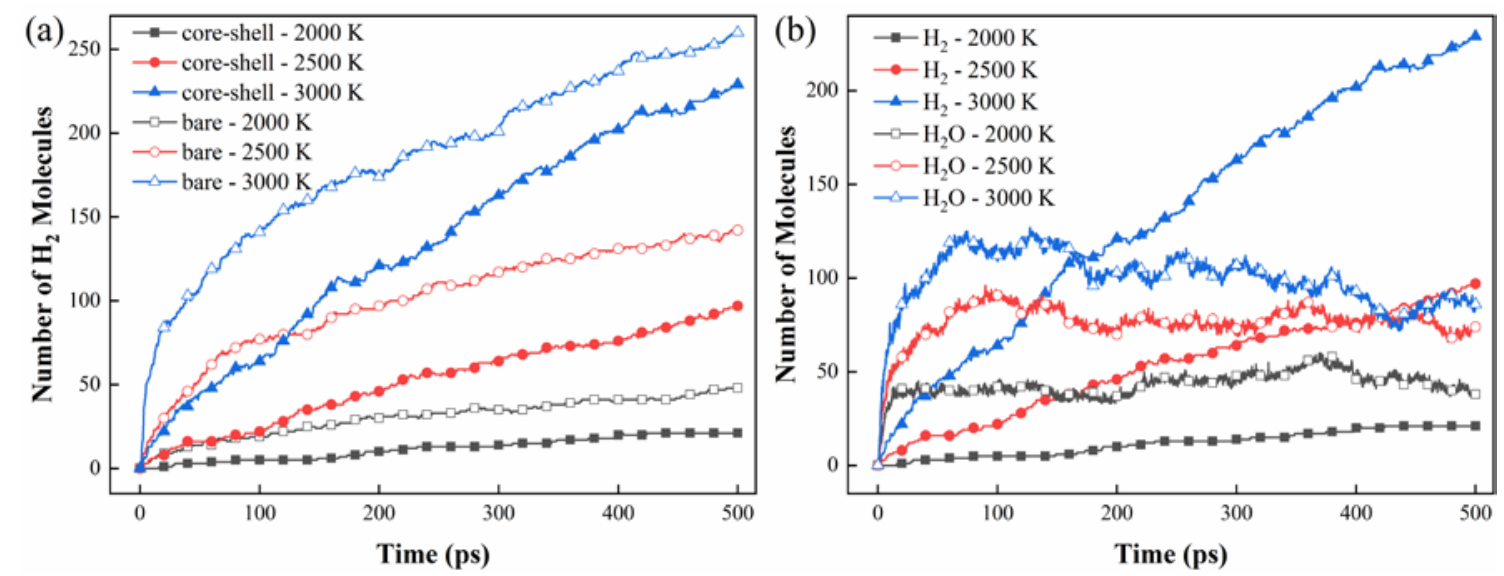

Figure 3. Time evolution of (a) number of $\mathrm{H}_{2}$ molecules for thermal decomposition of perfect coreshell $\mathrm{AlH}_{3}$ and bare $\mathrm{AlH}_{3}$, and (b) number of $\mathrm{H}_{2}$ and $\mathrm{H}_{2} \mathrm{O}$ molecules for thermal decomposition of perfect core-shell $\mathrm{AlH}_{3}$ at 2000, 2500 and $3000 \mathrm{~K}$.

At the early stage (about 0 - 16 ps) of thermal decomposition of perfect core-shell $\mathrm{AlH}_{3}$ at 2000 $\mathrm{K}$, a dramatically fast production of $\mathrm{H}_{2} \mathrm{O}$ (much faster than $\mathrm{H}_{2}$ ) is observed, followed by the relatively smooth fluctuation to the end. Similar results were observed at 2500 and $3000 \mathrm{~K}$, with the only difference that the peak and rate of $\mathrm{H}_{2} \mathrm{O}$ production is larger and quicker due to the higher temperature. This suggests that $\mathrm{H}_{2} \mathrm{O}$ is much more easily formed than $\mathrm{H}_{2}$ at the beginning of the reaction primarily as a result of the great availability of $\mathrm{O}$ atoms in the oxide layer. However, as the reaction progresses, the shell $\mathrm{O}$ atoms penetrate inside and the core $\mathrm{H}$ atoms diffuse outside simultaneously (more details presented in the next section), restraining the further rapid growth of $\mathrm{H}_{2} \mathrm{O}$ production because $\mathrm{H}_{2} \mathrm{O}$ (as well as $\mathrm{H}_{2}$ ) is only formed on the nanoparticle surface as shown in Figure 2. It is worth noting that in almost all the experiments [9, 20, 40, 42, 43, 45-48], $\mathrm{H}_{2}$ was a normal product of $\mathrm{AlH}_{3}$ thermal decomposition, but $\mathrm{H}_{2} \mathrm{O}$ was not observed or mentioned. Only Ismail and Hawkins [16] traced a tiny amount of $\mathrm{H}_{2} \mathrm{O}$ but they did not give any further explanation. The main reason for the significant $\mathrm{H}_{2} \mathrm{O}$ production in the present research is the huge difference of employed particle size and relative scale of oxide shell to $\mathrm{AlH}_{3}$ core between the simulation and experiment. The micron-size $\mathrm{AlH}_{3}$ was usually adopted in the experiment with a natural nano-size 
alumina surface layer [48], leading to an extremely small oxide shell to core ratio. In contrast, the particle size used in ReaxFF MD simulation is normally in nanometers as it is very computationally expensive to perform ReaxFF MD simulation on a micro-size particle. Consequently, in the experiment, the amount of $\mathrm{H}_{2} \mathrm{O}$ produced at the very beginning of the reaction would be too small and the process would be too fast to be captured by the detecting instrument. The greater number of core $\mathrm{H}$ atoms relative to shell $\mathrm{O}$ atoms makes the $\mathrm{H}_{2}$ production absolutely dominant later on. It can be summarized that the gap of the results of $\mathrm{H}_{2} \mathrm{O}$ and $\mathrm{H}_{2}$ production between the present study and real experiments is caused by the considerable difference of the adopted particle size and resulting different core-to-shell ratio. Previous literature [9, 18, 21, 42, 49] also reported particle size as a significant factor.

\subsubsection{Structural Evolution of Perfect Core-Shell AlH 3}

Figure 4 visualizes the structural evolution of perfect core-shell $\mathrm{AlH}_{3}$ nanoparticle at $2000 \mathrm{~K}$ by taking a snapshot of the nanoparticle central cross-section at different time instants. Compared with $\mathrm{t}$ $=0$ ps (Figure 1a2), at $\mathrm{t}=2 \mathrm{ps}$, plenty of $\mathrm{H}$ atoms diffuse into the shell and to the nanoparticle surface. Meanwhile, it can be seen that some shell $\mathrm{O}$ atoms move inward slightly. At $\mathrm{t}=5 \mathrm{ps}$, while this $\mathrm{H}$ and $\mathrm{O}$ two-way movement continues, the core and shell $\mathrm{Al}$ atoms also start to exchange and the core-shell boundary is shrinking. At $\mathrm{t}=10 \mathrm{ps}$, the amount of core $\mathrm{H}$ atoms is obviously less and shell $\mathrm{O}$ atoms move further inward but the exchange of core and shell $\mathrm{Al}$ atoms does not progress much. By time 40 ps, the core-shell structure becomes vague and the area of mixed core and shell $\mathrm{Al}$ atoms increases. At $\mathrm{t}=130 \mathrm{ps}$, the core-shell structure completely disappears and all core-shell atoms are mutually blended. There is no apparent difference between the structure at 500 ps and 130 ps, during which the atomic diffusion is steadily progressing. In short, the structural evolution of perfect core-shell $\mathrm{AlH}_{3}$ nanoparticle proceeds in three main stages: (1) Pre-diffusion: core $\mathrm{H}$ atoms diffuse outward throughout the shell to the surface and shell $\mathrm{O}$ atoms move inward; (2) Core-shell 
integration: core and shell $\mathrm{Al}$ atoms exchange and mix accompanied by the shrinking of core-shell boundary; and (3) Post-diffusion: core-shell structure completely vanishes and all mixed core-shell atoms steadily diffuse around. If the simulation is long enough, it would be expected to see that most of the $\mathrm{H}$ atoms are released as $\mathrm{H}_{2}$, leaving the pure $\mathrm{Al}$ core with limited $\mathrm{O}$ atoms inside. The whole process agrees well with the hydrogen desorption mechanism proposed by Kato et al. [50] based on their in situ x-ray photoelectron spectroscopy surface analysis, which found that $\mathrm{AlH}$ з only decomposes into $\mathrm{Al}$ and $\mathrm{H}_{2}$ at the free surface instead of the bulk, and is comparable with the recognized mechanism of $\mathrm{Al}$ nucleation and growth $[9,16]$. More importantly, the results in the present study provide a detailed atomistic insight of the process. To be specific, the procedure of $\mathrm{Al}$ nucleation and growth could be correlated to the three distinctive stages and the nucleation process can be identified in Figure 4. Figure 1a2 shows the initial state of the core-shell nanoparticle after relaxation, where the core $\mathrm{Al}$ and $\mathrm{H}$ atoms are evenly distributed. After the Pre-diffusion stage and when the reaction proceeds to the Core-shell integration stage, the distance between the $\mathrm{Al}$ atoms becomes closer and closer (snapshots of 10 and 40 ps in Figure 4). Especially at 40 ps, a number of local Al nucleation sites can be clearly recognized. However, because of the penetration of shell O atoms into the core, there are also $\mathrm{O}$ atoms present in between the nucleated $\mathrm{Al}$ atoms, which should be different from the 'pure' $\mathrm{Al}$ nucleation sites in the experiment using a micro-size particle. Then during the Post-diffusion stage with the ongoing release of $\mathrm{H}_{2}$, more and more nucleation sites emerge (snapshots of 130 and 500 ps in Figure 4). Because the degree of dehydrogenation within the studied simulation time scale is low, the Al growth is not observed in Figure 4. But it can be deduced that the nucleation sites will grow as the $\mathrm{H}$ atoms diffuse outward and leave the nanoparticle as $\mathrm{H}_{2}$. The final oxygen content of the nanoparticle depends on the particle size and shell thickness. 

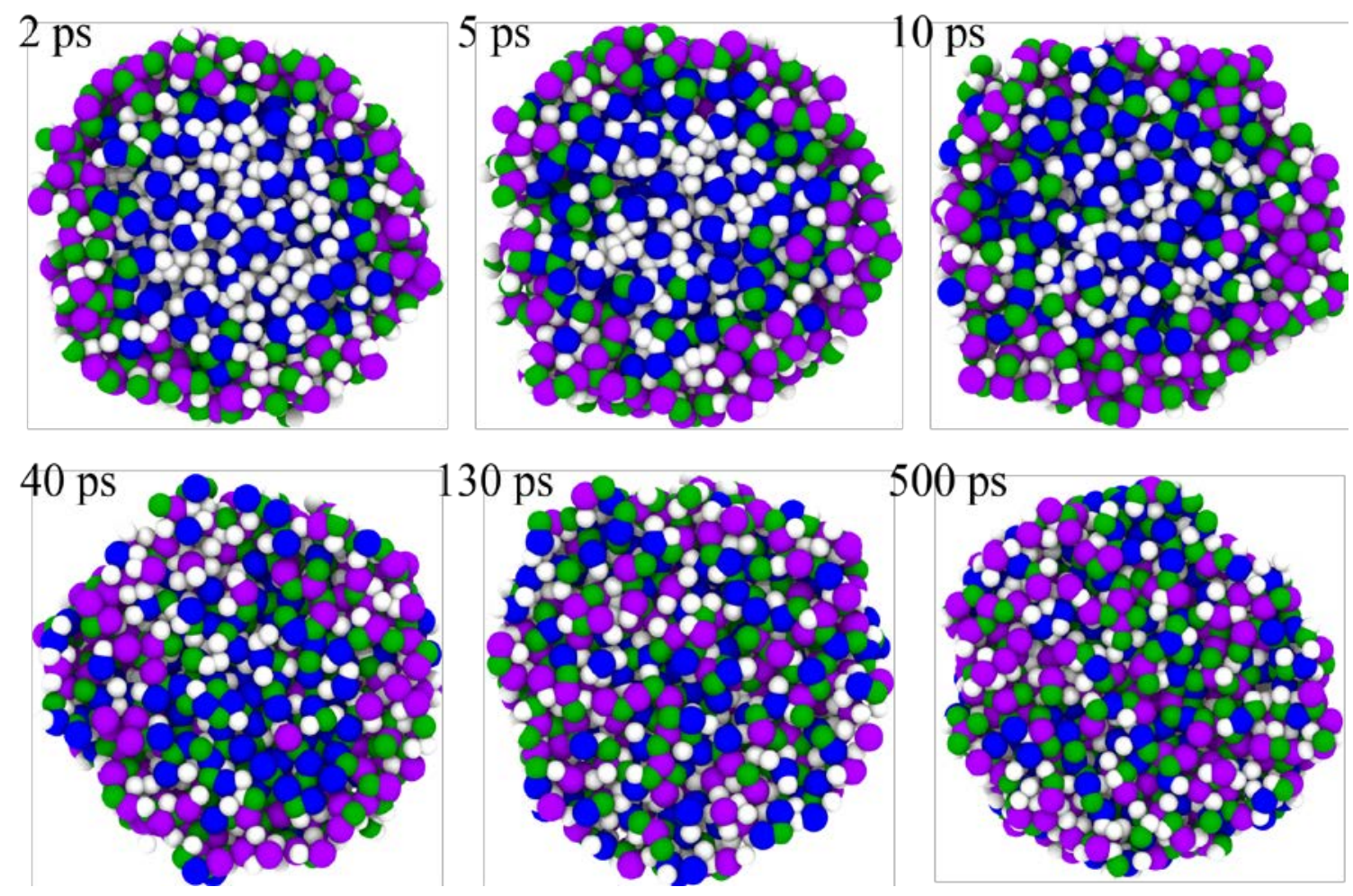

Figure 4. Snapshots of the central cross sections of perfect core-shell $\mathrm{AlH}_{3}$ nanoparticle structure in the thermal decomposition reaction at $2000 \mathrm{~K}$. The snapshot at 0 ps is shown in Figure 1a2.

\subsubsection{Diffusion of Atoms}

The mean square displacement (MSD) of $\mathrm{Al}, \mathrm{H}$ and $\mathrm{O}$ atoms of perfect core-shell $\mathrm{AlH}_{3}$ nanoparticle over time at 2000, 2500 and $3000 \mathrm{~K}$ are calculated and displayed in Figure 5. Only the nanoparticle atoms are considered for calculating the MSD, which means the atom is excluded in the calculation from the instant when it leaves the nanoparticle. The initial sharp increase of $\mathrm{MSD}_{\mathrm{H}}$ is caused by the rapid movement and outward diffusion of core $\mathrm{H}$ atoms into the shell. The MSDo line is above the $\mathrm{MSD}_{\mathrm{Al}}$ line because shell $\mathrm{O}$ atoms diffuse into the core and they travel a longer distance with a quicker speed than $\mathrm{Al}$ atoms. The results are consistent with the findings in Section 3.1.2. As time progresses, the MSDH becomes the lowest line among the three, when the diffusion of $\mathrm{O}$ and $\mathrm{Al}$ atoms plays a more leading role in the reaction, and this moment comes earlier as the temperature increases. 
Within the studied simulation time scale, all of the three MSDs show a faster rate (faster diffusion of atoms) at the early stage with the rising temperature. Although the MSDs at $2500 \mathrm{~K}$ have the highest peak values in Figure 5, those maximums should actually be the highest at $2000 \mathrm{~K}$ if the simulation is extended enough to witness those peaks. On the one hand, it can be seen from the figure trends that the MSDs at $2000 \mathrm{~K}$ are still climbing and their end values are close to those peak values at $2500 \mathrm{~K}$; the MSDs at $2500 \mathrm{~K}$ have reached their peaks and just start to decrease; the MSDs at $3000 \mathrm{~K}$ have already shown a smooth vibration. Consequently, it is reasonable to deduce that the peak MSD values at $2000 \mathrm{~K}$ should be higher than those at $2500 \mathrm{~K}$. On the other hand, because the focus is on the diffusion of atoms within the nanoparticle, it is necessary to exclude the atoms which have left the nanoparticle and are able to move much faster and more freely in the MSD calculation as mentioned above. For this reason, combined with the observation that high temperature enhances the thermal decomposition with a faster reaction rate (second paragraph of Section 3.1.1), more atoms leave the nanoparticle as gas products or radicals at the early stage and the reaction progresses to the steady diffusion stage earlier at high temperature than at low temperature. As a result, the internal diffusion of atoms rather than rapid release of products at low temperature is more dominant than that at high temperature leading to the highest MSD peak values at $2000 \mathrm{~K}$ among the three temperatures. However, the most important is that the evolution tendency of the MSD lines at three temperatures should be the same (provided that the simulations are long enough) and the evolution progresses faster at higher temperatures, which also backs up the concluded temperature dependency relationship.
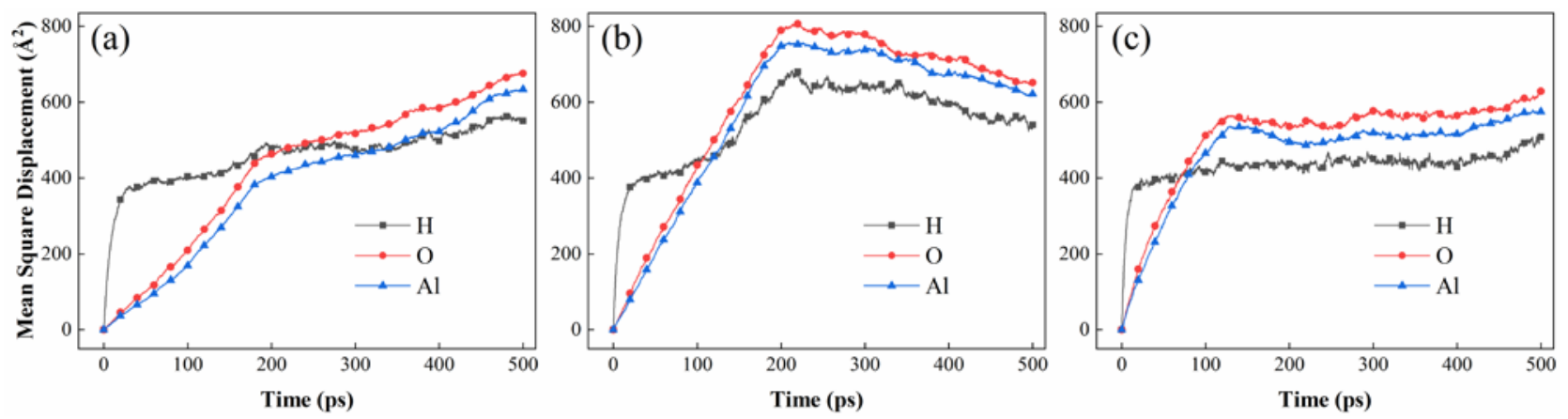
Figure 5. Mean square displacement of $\mathrm{Al}, \mathrm{H}$ and $\mathrm{O}$ atoms of perfect core-shell $\mathrm{AlH}_{3}$ nanoparticle during thermal decomposition at (a) $2000 \mathrm{~K}$, (b) $2500 \mathrm{~K}$ and (c) $3000 \mathrm{~K}$.

\subsection{Oxidation of Perfect and Defective Core-Shell $\mathrm{AlH}_{3}$}

\subsubsection{Effects of Defect and Time Evolution of Potential Energy, Temperature and Main Species}

As can be seen in Figure 6, the existence of the defect clearly accelerates the oxidation of coreshell AlH3. Specifically, the decrease of relative potential energy, increase of temperature and consumption rate of $\mathrm{O}_{2}$ is faster in the system with defective core-shell $\mathrm{AlH}_{3}$, which indicates a faster reaction rate. The defectiveness was reported to be an important factor on the kinetics of $\mathrm{AlH}_{3}$ reactions in previous experimental [18, 42, 51] and theoretical [52] studies. It is believed that defects play a crucial role in the initiation of $\mathrm{AlH}_{3}$ reaction and that a higher defect concentration could result in faster reaction. In the present study, it is found that the defect actually provides a fast track for the diffusion of atoms, especially $\mathrm{H}$ and $\mathrm{O}$ atoms. In other words, it facilitates the direct contact of core $\mathrm{AlH}_{3}$ and ambient $\mathrm{O}_{2}$. Therefore, in and around the defect area, the $\mathrm{H}$ and $\mathrm{O}$ atoms could easily diffuse outward and inward, respectively, and do not have to pass through the oxide layer. Then, with the outward diffusion of $\mathrm{H}$ atoms and consequent shrinking of core $\mathrm{AlH}_{3}$, the surface layer defect closes gradually. Finally, after the closure of the defect, the whole nanoparticle acts like the perfect core-shell $\mathrm{AlH}_{3}$ at the same stage. In brief, the defect enhances the initiation of $\mathrm{AlH}_{3}$ oxidation and accelerates the oxidation at the early stage of the reaction. It is foreseeable that the reaction could be much faster with the increasing size and number of the defect.

Similar to the thermal decomposition of perfect core-shell $\mathrm{AlH}_{3}$, the production of $\mathrm{H}_{2} \mathrm{O}$ is significant in the oxidation simulations. In the oxygen environment, likewise, $\mathrm{H}_{2} \mathrm{O}$ is preferentially formed relative to $\mathrm{H}_{2}$ at the early stage of the reaction, the significant extent of which can be seen in Figure 6b. However, in a reported experiment [53], $\mathrm{H}_{2} \mathrm{O}$ was considered as a product of $\mathrm{H}_{2} / \mathrm{O}_{2}$ reaction after the $\mathrm{H}_{2}$ release. In addition to the discussion and explanation given in the last paragraph 
of Section 3.1.1., the high surface-to-volume ratio of nanoparticle also contributes to the great amount of $\mathrm{H}_{2} \mathrm{O}$ generated. Because of the relatively much larger surface area than a micron-size particle, the contact area of the nanoparticle with $\mathrm{O}_{2}$ is much larger, thereby adsorbing more $\mathrm{O}_{2}$ molecules. Together with the small radius, the penetrability of $\mathrm{O}$ atoms is better. As a result, the abundant availability of $\mathrm{O}$ atoms leads to the remarkable and fast production of $\mathrm{H}_{2} \mathrm{O}$ at the early stage. The oxygen pressure and equivalence ratio could be other influential factors and will be investigated in the future work. After about 200 ps and when the $\mathrm{H}_{2} \mathrm{O}$ production is steady, production of $\mathrm{H}_{2}$ starts to increase. However, most of the $\mathrm{H}$ atoms are consumed as $\mathrm{H}_{2} \mathrm{O}$ due to the aforementioned reasons, which accounts for the minor observation of $\mathrm{H}_{2}$ in the present simulation. It is certain that $\mathrm{H}_{2}$ production would dominant in a later stage if a micro-size particle is adopted. The combined effect of particle size and surface-to-volume ratio causes the gap between the results from the present research and real experiments. Apart from $\mathrm{H}_{2} \mathrm{O}$ and $\mathrm{H}_{2}, \mathrm{OH}$ is also a noticeable species in the oxidation reaction. It begins to form from nearly the same time (slightly after) as $\mathrm{H}_{2} \mathrm{O}$ production and before $\mathrm{H}_{2}$ release. The $\mathrm{OH}$ generation in the thermal decomposition reaction is negligible. Hence, it is the $\mathrm{O}_{2}$ that promotes the production of $\mathrm{OH}$.
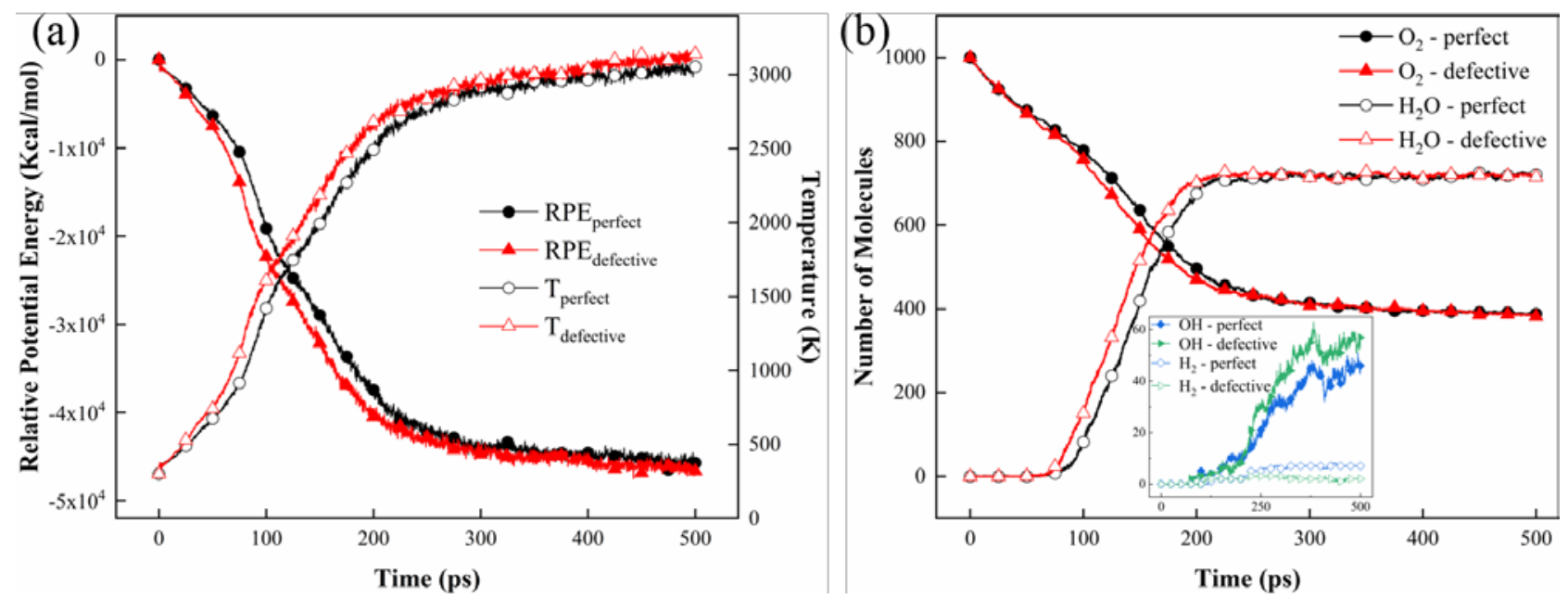

Figure 6. Time evolution of (a) relative energy and temperature, and (b) main species for oxidation of perfect and defective core-shell $\mathrm{AlH}_{3}$. 


\subsubsection{Reaction of Perfect Core-Shell $\mathrm{AlH}_{3}$ with $\mathrm{O}_{2}$}

The detailed interaction of perfect core-shell $\mathrm{AlH}_{3}$ with $\mathrm{O}_{2}$ is monitored to investigate the oxidation process. It is observed that $\mathrm{O}_{2}$ molecules head towards the nanoparticle surface rapidly when the reaction starts. After reaching the surface, one $\mathrm{O}$ atom could be attached to one single $\mathrm{Al}$ atom or stuck in the middle of two adjacent $\mathrm{Al}$ atoms with the other $\mathrm{O}$ atom vertically (to the surface) hanging in the air (Figure 7a). After a while, in the same way, the other $\mathrm{O}$ atom would lay down on the surface sticking to another one or two $\mathrm{Al}$ atoms (Figure $7 \mathrm{~b}$ ). Next, the $\mathrm{O}-\mathrm{O}$ bond is broken and the two $\mathrm{O}$ atoms are able to move freely. This explains why Figure $6 \mathrm{~b}$ demonstrates that the number of $\mathrm{O}_{2}$ reduces from the very beginning but there is no product formation during the first tens of ps. It is as a result of this oxygen adsorption-decomposition process, which sees increased O availability for the next stage of the reaction but does not itself produce any oxidation species. This process goes quicker as the temperature increases. Subsequently, along with the outward diffusion of core $\mathrm{H}$ atoms, the products start to form and be released successively. The formation mechanisms of $\mathrm{H}_{2} \mathrm{O}$ and $\mathrm{H}_{2}$ are the same as elucidated in the first paragraph of Section 3.1.1. The nanoparticle simply includes far more $\mathrm{O}$ atoms derived from the ambient $\mathrm{O}_{2}$ molecules. The $\mathrm{OHs}$ mentioned before are mainly generated from the nanoparticle but a small number of OHs are found to be the product of reaction of some species like $\mathrm{HO}_{2}$ at high temperature, which is not detailed here. It is noteworthy that the $\mathrm{OH}$ is not directly released from an $\mathrm{OH}$ unit (Figure 2b3) on the nanoparticle surface but relevant to the adsorbed $\mathrm{O}_{2}$ molecules. When the $\mathrm{O}_{2}$ molecule is vertically adsorbed on the surface with one $\mathrm{O}$ atom freely hanging in the air, a nearby $\mathrm{H}$ atom could bond to it (Figure 7c) and then this $\mathrm{OH}$ is detached from the adsorbed $\mathrm{O}$ atom, which is the preferred way of producing $\mathrm{OH}$. Therefore, this is the reason that $\mathrm{OH}$ production in the thermal decomposition reaction is negligible and illustrates how $\mathrm{O}_{2}$ promotes the production of $\mathrm{OH}$. 

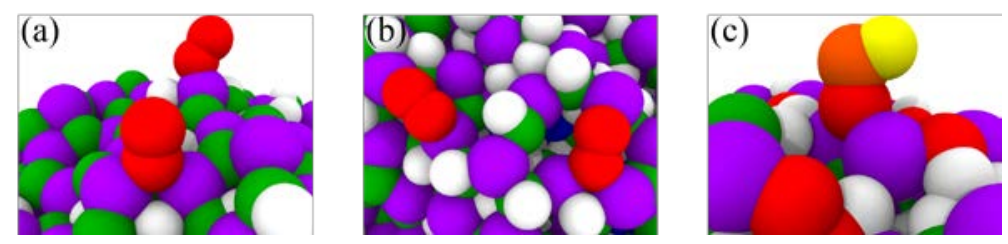

Figure 7. Illustration of how $\mathrm{O}_{2}$ molecules are (a) initially and (b) finally adsorbed on the nanoparticle surface, and (c) how $\mathrm{OH}$ is produced on top of the adsorbed $\mathrm{O}_{2}$ molecule. The highlighted $\mathrm{H}$ and $\mathrm{O}$ atoms are in yellow and orange, respectively.

The structural evolution of the nanoparticle is shown in Figure 8. Corresponding to Figure 6b, at $\mathrm{t}=50$ ps when there is no product formation, many $\mathrm{O}_{2}$ molecules are adsorbed on the nanoparticle surface. The $\mathrm{O}-\mathrm{O}$ bond has not been broken yet and no $\mathrm{O}$ atom from the ambient $\mathrm{O}_{2}$ has penetrated inside the nanoparticle. In the meantime, more core $\mathrm{H}$ atoms diffuse into the shell and to the surface compared with $t=0$ ps (Figure 1a2). Shell $\mathrm{O}$ atoms start to diffuse into the core as well. With the fast reaction, at $\mathrm{t}=120 \mathrm{ps}$, a large amount of $\mathrm{H}$ atoms have left the nanoparticle and shell $\mathrm{O}$ atoms enter into the core. Simultaneously, the ambient $\mathrm{O}$ atoms advance into the nanoparticle as free $\mathrm{O}$ atoms. Coming to $\mathrm{t}=160 \mathrm{ps}$, the $\mathrm{H}$ atoms are lesser and ambient $\mathrm{O}$ atoms go further towards the nanoparticle core. Core and shell $\mathrm{Al}$ atoms begin to exchange and the core-shell boundary is shrinking. Until t $=180 \mathrm{ps,}$ only a small amount of $\mathrm{H}$ atoms can be seen in the nanoparticle. The whole nanoparticle is distributed with ambient $\mathrm{O}$ atoms, and core/shell $\mathrm{Al}$ atoms are mixed interchangeably. From this point to the end of the simulation, a continuous supply of ambient $\mathrm{O}$ atoms gradually flow into the nanoparticle and core/shell Al atoms are uniformly integrated. At last, the nanoparticle consists primarily of $\mathrm{Al}$ and $\mathrm{O}$ with only few $\mathrm{H}$ atoms. Briefly, the oxidation process includes following three main stages: (I) Oxygen adsorption: ambient $\mathrm{O}_{2}$ molecules are quickly adsorbed on the nanoparticle surface accompanied by the diffusion of inner atoms; (II) Fast dehydrogenation: $\mathrm{O}-\mathrm{O}$ bond of $\mathrm{O}_{2}$ is broken and these ambient $\mathrm{O}$ atoms penetrate into the nanoparticle with the fast products formation; and (III) Al oxidation: after most of the $\mathrm{H}$ atoms are released, the ambient $\mathrm{O}$ atoms oxidize the remaining nanoparticle. 

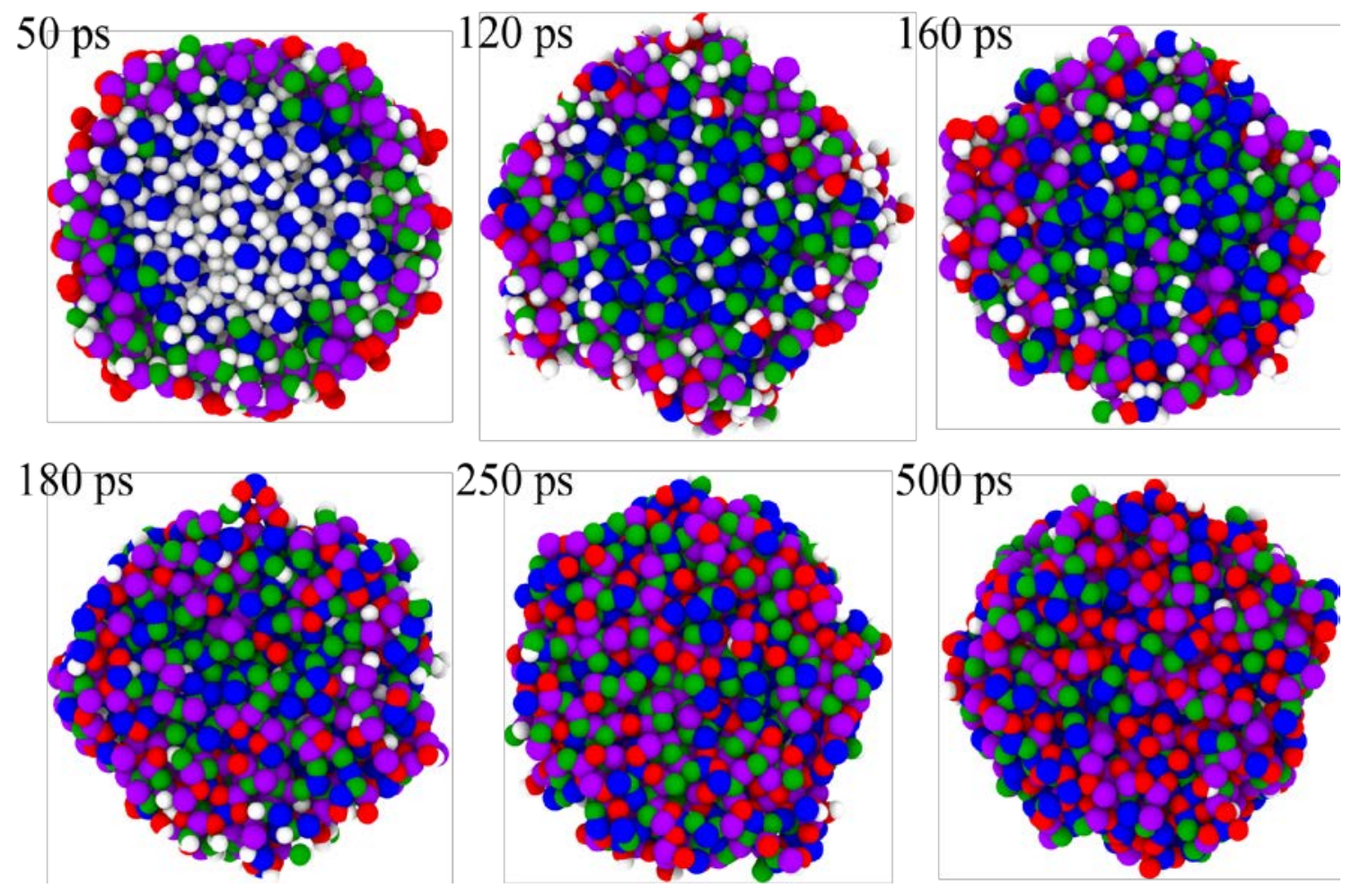

Figure 8. Snapshots of the central cross sections of perfect core-shell $\mathrm{AlH}_{3}$ nanoparticle structure in the oxidation reaction. The snapshot at 0 ps is shown in Figure $1 \mathrm{a} 2$.

The three distinctive stages can also be characterised based on the ratio between the numbers of $\mathrm{Al} / \mathrm{H} / \mathrm{O}$ atoms in the nanoparticle during the oxidation reaction as shown in Figure 9. Note that the number of $\mathrm{Al}$ atoms in the nanoparticle is unchanged during the simulation. At Stage I, O/Al increases, $\mathrm{H} / \mathrm{O}$ decreases and $\mathrm{H} / \mathrm{Al}$ almost remains constant because the nanoparticle is adsorbing the ambient $\mathrm{O}_{2}$ molecules and there is few products generation (only tiny reduction in $\mathrm{H} / \mathrm{O}$ at the end of Stage I). At Stage II, all of the three ratios evidently decrease on account of the fast dehydrogenation and products release from the nanoparticle. Particularly, more $\mathrm{H}$ than $\mathrm{O}$ atoms release and ongoing flow of ambient $\mathrm{O}$ atoms into the nanoparticle result in the further drop of H/O after Stage I. At Stage III, for the reason that the liberation of $\mathrm{H}$ atoms approaches its peak, both $\mathrm{H} / \mathrm{Al}$ and $\mathrm{H} / \mathrm{O}$ reduce slowly. On the contrary, $\mathrm{O} / \mathrm{Al}$ keeps increasing owing to the sustained supply of ambient $\mathrm{O}$ atoms, which means the nanoparticle is continuously oxidized and the degree of oxidation is elevating, although the oxidation rate is becoming slower as the reaction progresses. Therefore, a 
fully oxidized amorphous $\mathrm{Al}_{2} \mathrm{O}_{3}$ nanoparticle could be expected in the end if the simulation is continued long enough. While the oxidation process is generally in agreement with the simplified model that dehydrogenation of $\mathrm{AlH}_{3}$ occurs first followed by the $\mathrm{Al}$ oxidation [40], it is also observed in the present study that the dehydrogenation and oxidation actually proceed simultaneously although the oxidation rate is limited during the dehydrogenation period.

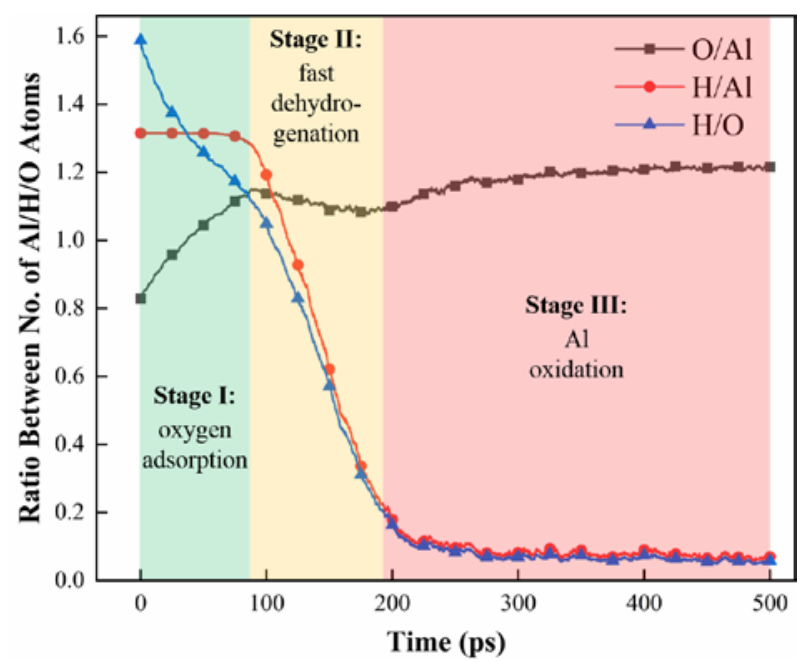

Figure 9. Ratio between the numbers of $\mathrm{Al} / \mathrm{H} / \mathrm{O}$ atoms in the nanoparticle during the oxidation reaction with the three distinctive stages characterised in three different colours.

Figure 10 describes the evolution of temperature distribution of the nanoparticle. Initially at $\mathrm{t}=$ 50 ps, a lot of hot spots ( $2000 \mathrm{~K})$ and high temperature areas ( $1000 \mathrm{~K})$ can be seen inside the nanoparticle and on the surface, which induce the adsorption and diffusion of the oxygen. At $t=120$ ps, part of these high temperature regions stand out and their temperature further rises to about 4000 $\mathrm{K}$. The temperature of the remaining area goes up accordingly. Then as the reaction progresses, the number and size of the high temperature regions (around or higher than $4000 \mathrm{~K}$ ) both increase, which is attributed to the dominant exothermic oxidation of Al. Finally, the temperature distribution of the nanoparticle is equilibrated ( $\mathrm{t}=250 \mathrm{ps}$ and $500 \mathrm{ps}$ ) because the potential energy tends to be stable after about 200 ps. 

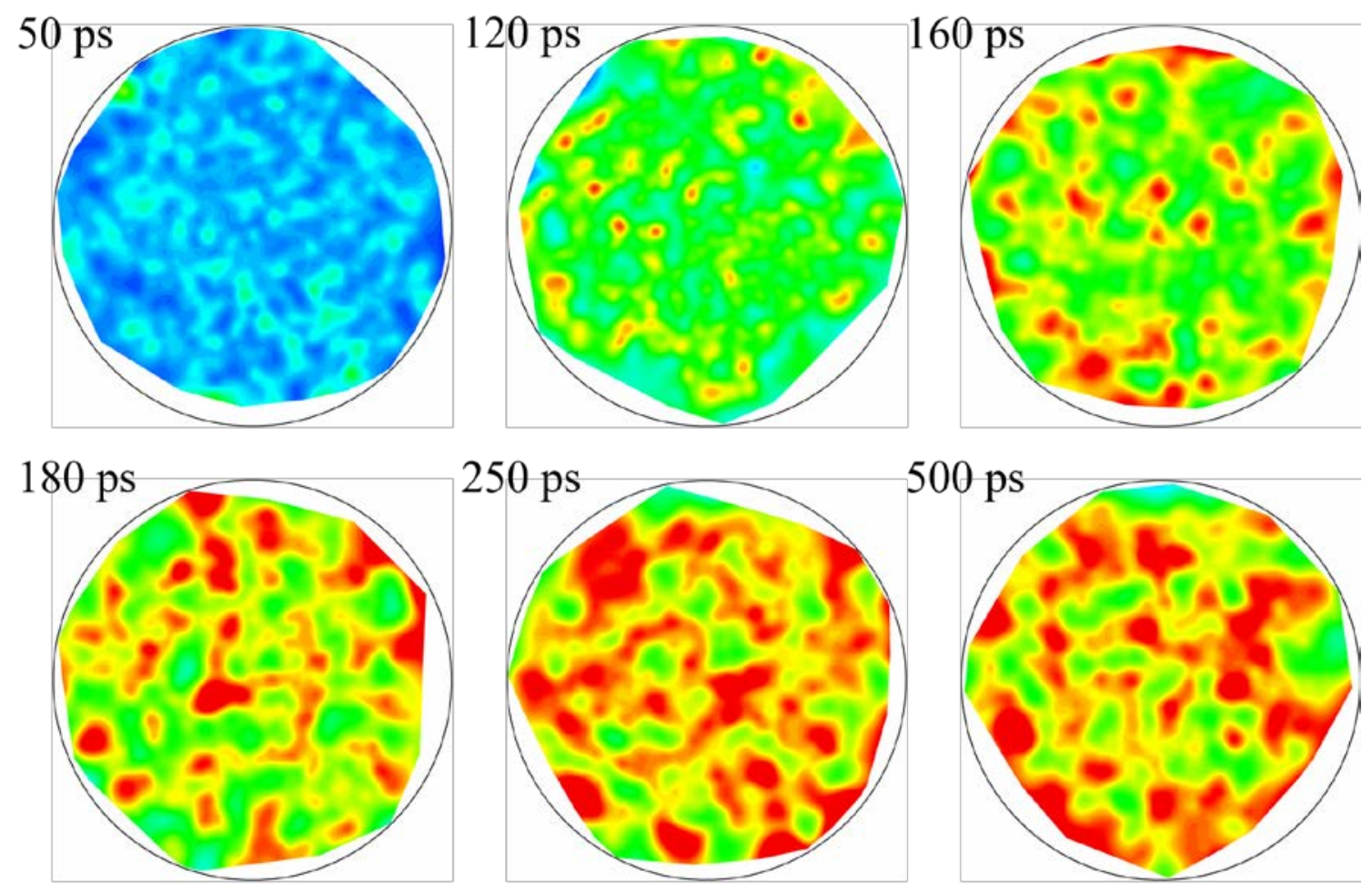

Temperature $(\mathrm{K})$

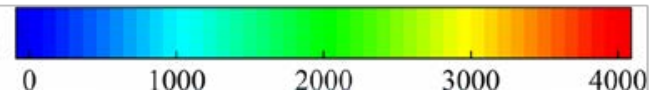

Figure 10. Snapshots of the central cross sections of perfect core-shell $\mathrm{AlH} 3$ nanoparticle temperature distribution in the oxidation reaction.

\section{CONCLUSIONS}

ReaxFF MD simulations have been performed to investigate the fundamental reaction mechanisms of thermal decomposition and oxidation of $\mathrm{AlH}_{3}$. The results illustrate the detailed process and mechanism of $\mathrm{H}_{2}$ and $\mathrm{H}_{2} \mathrm{O}$ formation in the $\mathrm{AlH}_{3}$ reaction. The thermal decomposition is found to be temperature dependent, and high temperature enhances the process via a faster reaction rate. Due to the existence of the oxide layer, $\mathrm{H}_{2}$ production of perfect core-shell $\mathrm{AlH}_{3}$ during the thermal decomposition is slower than that of bare $\mathrm{AlH}_{3}$ as the $\mathrm{H}$ atoms have to travel across the oxide layer to the nanoparticle surface. Significant $\mathrm{H}_{2} \mathrm{O}$ production is observed in the thermal decomposition of perfect core-shell $\mathrm{AlH}_{3}$ and the results suggest that $\mathrm{H}_{2} \mathrm{O}$ is much more easily formed than $\mathrm{H}_{2}$ at the beginning of the reaction. The structural evolution of perfect core-shell $\mathrm{AlH}_{3}$ 
proceeds in three main stages: (1) Pre-diffusion: core H atoms diffuse outward throughout the shell to the surface and shell $\mathrm{O}$ atoms move inward; (2) Core-shell integration: core and shell $\mathrm{Al}$ atoms exchange and mix accompanied by the shrinking of core-shell boundary; and (3) Post-diffusion: core-shell structure completely vanishes and all mixed core-shell atoms steadily diffuse around. The mean square displacement results are consistent with the findings from the structural evolution and further confirm the above temperature dependency relationship. For the oxidation, the results indicate that the defect enhances the initiation of core-shell $\mathrm{AlH}_{3}$ oxidation and accelerates the oxidation at the early stage of the reaction. It provides a fast track for the diffusion of atoms, especially $\mathrm{H}$ and $\mathrm{O}$ atoms, thereby facilitating the direct contact of core $\mathrm{AlH}_{3}$ and ambient $\mathrm{O}_{2}$. Similar to the thermal decomposition process, $\mathrm{H}_{2} \mathrm{O}$ production is also pronounced in the oxidation and $\mathrm{H}_{2} \mathrm{O}$ is preferentially formed relative to $\mathrm{H}_{2}$ at the beginning of the reaction. Besides $\mathrm{H}_{2} \mathrm{O}$ and $\mathrm{H}_{2}$, $\mathrm{OH}$ is a noticeable species in the oxidation reaction. The detailed interaction of perfect core-shell $\mathrm{AlH}_{3}$ with $\mathrm{O}_{2}$ is monitored to demonstrate how $\mathrm{O}_{2}$ promotes the production of $\mathrm{OH}$. It is concluded from the structural evolution of perfect core-shell $\mathrm{AlH}_{3}$ that the oxidation also includes three main stages: (I) Oxygen adsorption: ambient $\mathrm{O}_{2}$ molecules are quickly adsorbed on the nanoparticle surface accompanied by the diffusion of inner atoms; (II) Fast dehydrogenation: $\mathrm{O}-\mathrm{O}$ bond of $\mathrm{O}_{2}$ is broken and these ambient $\mathrm{O}$ atoms penetrate into the nanoparticle with fast products formation; and (III) $\mathrm{Al}$ oxidation: after most $\mathrm{H}$ atoms are released, the ambient $\mathrm{O}$ atoms oxidize the remaining nanoparticle. It is found that the dehydrogenation and oxidation proceed simultaneously although the oxidation rate is limited during the dehydrogenation period.

The results obtained from the present research are applicable to those high-temperature thermal decomposition and oxidation reactions of $\mathrm{AlH}_{3}$, which normally occur in propulsion systems. The revealed mechanisms may benefit the control of hydrogen release leading to the safe storage and efficient usage of $\mathrm{AlH}_{3}$. For example, to reduce the instability resulted from the defects and preserve the high hydrogen capacity during storage, an additional thin oxide layer or other suitable organic 
layer could be coated on the $\mathrm{AlH}_{3}$ surface that potentially makes it a more efficient propellant. Furthermore, if the thermal stability of $\mathrm{AlH}_{3}$ could be effectively increased, the nanoparticle $\mathrm{AlH}_{3}$ would be very promising. The reason is that the oxide layer does not have much negative impact on the oxidation reaction as the relatively rich availability of shell $\mathrm{O}$ with respect to core $\mathrm{H}$ atoms could promote the $\mathrm{H}_{2} \mathrm{O}$ production at the beginning thereby facilitating the reaction. Also, the reaction kinetics is expected to be enhanced due to the high specific surface area of nanoparticle. Therefore, this research provides the theoretical foundation for improving the practical applications of $\mathrm{AlH}_{3}$.

\section{ACKNOWLEDGEMENTS}

Funding from the UK Engineering and Physical Sciences Research Council under the project “UK Consortium on Mesoscale Engineering Sciences (UKCOMES)” (Grant No. EP/R029598/1), and from the National Natural Science Foundation of China (Grant No. 51706057) and Open Research Fund Program of Science and Technology of Aerospace Chemical Power Laboratory (Grant No. STACPL220181B02-2) is gratefully acknowledged. The first author is also grateful for the Graduate Research Scholarship and Overseas Research Scholarship from University College London.

Declarations of Interest: none

\section{REFERENCES}

[1] Ahluwalia RK, Hua TQ, Peng JK. Automotive storage of hydrogen in alane. Int J Hydrogen Energ 2009;34(18):7731-40.

[2] DeLuca LT, Galfetti L, Severini F, Rossettini L, Meda L, Marra G, et al. Physical and ballistic characterization of AlH3-based space propellants. Aerosp Sci Technol 2007;11(1):18-25. 
[3] Guery JF, Chang IS, Shimada T, Glick M, Boury D, Robert E, et al. Solid propulsion for space applications: An updated roadmap. Acta Astronaut 2010;66(1-2):201-19.

[4] Sakintuna B, Lamari-Darkrim F, Hirscher M. Metal hydride materials for solid hydrogen storage: A review. Int J Hydrogen Energ 2007;32(9):1121-40.

[5] Shark SC, Pourpoint TL, Son SF, Heister SD. Performance of Dicyclopentadiene/H2O2Based Hybrid Rocket Motors with Metal Hydride Additives. J Propul Power 2013;29(5):1122-9.

[6] Graetz J, Reilly J, Sandrock G, Johnson J, Zhou W, Wegrzyn J. Aluminum hydride, AlH3, as a hydrogen storage compound. . 2006.

[7] Graetz J, Reilly JJ. Thermodynamics of the alpha, beta and gamma polymorphs of AlH3. J Alloy Compd 2006;424(1-2):262-5.

[8] Maehlen JP, Yartys VA, Denys R, Fichtner M, Frommen C, Bulychev BM, et al. Thermal decomposition of AlH3 studied by in situ synchrotron X-ray diffraction and thermal desorption spectroscopy. J Alloy Compd 2007;446:280-9.

[9] Bazyn T, Krier H, Glumac N, Shankar N, Wang X, Jackson TL. Decomposition of aluminum hydride under solid rocket motor conditions. J Propul Power 2007;23(2):457-64.

[10] Graetz J, Reilly JJ, Kulleck JG, Bowman RC. Kinetics and thermodynamics of the aluminum hydride polymorphs. J Alloy Compd 2007;446:271-5.

[11] Finholt AE, Bond AC, Schlesinger HI. Lithium Aluminum Hydride, Aluminum Hydride and Lithium Gallium Hydride, and Some of Their Applications in Organic and Inorganic Chemistry. J Am Chem Soc 1947;69(5):1199-203.

[12] Connell TL, Risha GA, Yetter RA, Young G, Sundaram DS, Yang V. Combustion of alane and aluminum with water for hydrogen and thermal energy generation. P Combust Inst 2011;33:1957-65. 
[13] Young G, Piekiel N, Chowdhury S, Zachariah MR. Ignition Behavior of alpha-AIH(3). Combust Sci Technol 2010;182(9):1341-59.

[14] Young G, Risha GA, Miller AG, Glass RA, Connell J, Terrence L., Yetter RA. Combustion of alane-based solid fuels. 2010;9(3):249-66.

[15] Graetz J, Reilly JJ, Yartys VA, Maehlen JP, Bulychev BM, Antonov VE, et al. Aluminum hydride as a hydrogen and energy storage material: Past, present and future. J Alloy Compd 2011;509:S517-S28.

[16] Ismail IMK, Hawkins T. Kinetics of thermal decomposition of aluminium hydride: I-nonisothermal decomposition under vacuum and in inert atmosphere (argon). Thermochim Acta 2005;439(1-2):32-43.

[17] Paraskos A, Hanks J, Lund G. Synthesis and Characterization of Alpha Alane. Miami: IMEM Conference; 2007.

[18] Tarasov VP, Muravlev YB, Bakum SI, Novikov AV. Kinetics of formation of metallic aluminum upon thermal and photolytic decomposition of aluminum trihydride and trideuteride as probed by NMR. Dokl Phys Chem 2003;393(4-6):353-6.

[19] Weiser V, Eisenreich N, Koleczko A, Roth E. On the oxidation and combustion of AlH3 a potential fuel for rocket propellants and gas generators. Propell Explos Pyrot 2007;32(3):21321.

[20] Gabis I, Dobrotvorskiy M, Evard E, Voyt A. Kinetics of dehydrogenation of MgH2 and AlH3. J Alloy Compd 2011;509:S671-S4.

[21] Gabis IE, Voyt AP, Chernov IA, Kuznetsov VG, Baraban AP, Elets DI, et al. Ultraviolet activation of thermal decomposition of alpha-alane. Int J Hydrogen Energ 2012;37(19):14405-12.

[22] Nakagawa Y, Isobe S, Wang YM, Hashimoto N, Ohnuki S, Zeng L, et al. Dehydrogenation process of AlH3 observed by TEM. J Alloy Compd 2013;580:S163-S6. 
[23] Nakagawa Y, Lee CH, Matsui K, Kousaka K, Isobe S, Hashimoto N, et al. Doping effect of Nb species on hydrogen desorption properties of AlH3. J Alloy Compd 2018;734:55-9.

[24] Senftle TP, Hong S, Islam MM, Kylasa SB, Zheng Y, Shin YK, et al. The ReaxFF reactive force-field: development, applications and future directions. npj Computational Materials 2016;2:15011.

[25] Ashraf C, van Duin ACT. Extension of the ReaxFF Combustion Force Field toward Syngas Combustion and Initial Oxidation Kinetics. J Phys Chem A 2017;121(5):1051-68.

[26] Chenoweth K, van Duin ACT, Goddard WA, 3rd. ReaxFF reactive force field for molecular dynamics simulations of hydrocarbon oxidation. J Phys Chem A 2008;112(5):1040-53.

[27] Russo MF, van Duin ACT. Atomistic-scale simulations of chemical reactions: Bridging from quantum chemistry to engineering. Nucl Instrum Meth B 2011;269(14):1549-54.

[28] van Duin ACT, Dasgupta S, Lorant F, Goddard WA. ReaxFF: A reactive force field for hydrocarbons. J Phys Chem A 2001;105(41):9396-409.

[29] Chu QZ, Shi BL, Liao LJ, Luo KH, Wang NF, Huang CG. Ignition and Oxidation of CoreShell Al/Al2O3 Nanoparticles in an Oxygen Atmosphere: Insights from Molecular Dynamics Simulation. J Phys Chem C 2018;122(51):29620-7.

[30] Feng M, Jiang XZ, Luo KH. A reactive molecular dynamics simulation study of methane oxidation assisted by platinum/graphene-based catalysts. P Combust Inst 2019;37(4):547380.

[31] Mao Q, van Duin ACT, Luo KH. Investigation of methane oxidation by palladium-based catalyst via ReaxFF Molecular Dynamics simulation. P Combust Inst 2017;36(3):4339-46.

[32] Feng M, Jiang XZ, Mao Q, Luo KH, Hellier P. Initiation mechanisms of enhanced pyrolysis and oxidation of JP-10 (exo-tetrahydrodicyclopentadiene) on functionalized graphene sheets: Insights from ReaxFF molecular dynamics simulations. Fuel 2019;254:115643. 
[33] Jiang XZ, Feng M, Zeng W, Luo KH. Study of mechanisms for electric field effects on ethanol oxidation via reactive force field molecular dynamics. P Combust Inst 2019;37(4):5525-35.

[34] Zhang YR, van Duin ACT, Luo KH. Investigation of ethanol oxidation over aluminum nanoparticle using ReaxFF molecular dynamics simulation. Fuel 2018;234:94-100.

[35] Feng M, Jiang XZ, Zeng W, Luo KH, Hellier P. Ethanol oxidation with high water content: A reactive molecular dynamics simulation study. Fuel 2019;235:515-21.

[36] Aktulga HM, Fogarty JC, Pandit SA, Grama AY. Parallel reactive molecular dynamics: Numerical methods and algorithmic techniques. Parallel Computing 2012;38(4):245-59.

[37] Plimpton S. Fast Parallel Algorithms for Short-Range Molecular Dynamics. Journal of Computational Physics 1995;117(1):1-19.

[38] Hong S, van Duin ACT. Atomistic-Scale Analysis of Carbon Coating and Its Effect on the Oxidation of Aluminum Nanoparticles by ReaxFF-Molecular Dynamics Simulations. J Phys Chem C 2016;120(17):9464-74.

[39] Ojwang JGO, van Santen RA, Kramer GJ, van Duin ACT, Goddard WA. Parametrization of a reactive force field for aluminum hydride. J Chem Phys 2009;131(4).

[40] Eisenreich N, Kessler A, Koleczko A, Weiser V. On the kinetics of AlH3 decomposition and the subsequent Al oxidation. Int J Hydrogen Energ 2014;39(11):6286-94.

[41] Stukowski A. Visualization and analysis of atomistic simulation data with OVITO-the Open Visualization Tool. Model Simul Mater Sc 2010;18(1).

[42] Graetz J, Reilly JJ. Decomposition kinetics of the AlH3 polymorphs. J Phys Chem B 2005;109(47):22181-5.

[43] Baranowski B, Tkacz M. The Equilibrium Between Solid Aluminium Hydride and Gaseous Hydrogen. Zeitschrift für Physikalische Chemie. 135. 1983:27. 
[44] Wang Y, Palsson GK, Raanaei H, Hjorvarsson B. The influence of amorphous Al2O3 coating on hydrogen uptake of materials. J Alloy Compd 2008;464(1-2):L13-L6.

[45] Gabis IE, Baraban AP, Kuznetsov VG, Elets DI, Dobrotvorskii MA, Voyt AP. A mechanism of ultraviolet activation of the alpha-AlH3 decomposition. Int J Hydrogen Energ 2014;39(28):15844-50.

[46] Grove H, Sorby MH, Brinks HW, Hauback BC. In situ synchrotron powder X-ray diffraction studies of the thermal decomposition of beta- and gamma-AlD3. J Phys Chem C 2007;111(44):16693-9.

[47] Humphries TD, Munroe KT, DeWinter TM, Jensen CM, McGrady GS. NMR spectroscopic and thermodynamic studies of the etherate and the alpha, alpha ', and gamma phases of AlH3. Int J Hydrogen Energ 2013;38(11):4577-86.

[48] Muto S, Tatsumi K, Ikeda K, Orimo S. Dehydriding process of alpha-AlH3 observed by transmission electron microscopy and electron energy-loss spectroscopy. J Appl Phys 2009;105(12).

[49] Sandrock G, Reilly J, Graetz J, Zhou WM, Johnson J, Wegrzyn J. Accelerated thermal decomposition of AlH3 for hydrogen-fueled vehicles. Appl Phys a-Mater 2005;80(4):687-90.

[50] Kato S, Bielmann M, Ikeda K, Orimo S, Borgschulte A, Zuttel A. Surface changes on AlH3 during the hydrogen desorption. Appl Phys Lett 2010;96(5).

[51] Herley PJ, Christofferson O, Todd JA. Microscopic Observations on the ThermalDecomposition of Alpha-Aluminum Hydride. J Solid State Chem 1980;35(3):391-401.

[52] Ismer L, Janotti A, Van de Walle CG. Point-defect-mediated dehydrogenation of AlH3. Appl Phys Lett 2010;97(20).

[53] Young G, Jacob R, Zachariah MR. High Pressure Ignition and Combustion of Aluminum Hydride. Combust Sci Technol 2015;187(9):1335-50. 